\title{
1 Dependence of maximum concentration from chemical accidents on release
}

2 duration

3

4 Steven Hanna ${ }^{\mathrm{a}}$, Joseph Chang ${ }^{\mathrm{b}}$

$5 \quad{ }^{\mathrm{a}}$ Hanna Consultants, 7 Crescent Ave., Kennebunkport, ME 04046 USA (207 9674478 ,

6 hannaconsult@ roadrunner.com)

$7 \quad{ }^{b}$ Homeland Security Studies and Analysis Institute, Falls Church, VA, USA
8

9 Abstract

10

11

12

13

14

15

16

17

18

19

20

21

22

23

24

Chemical accidents often involve releases of a total mass, Q, of stored material in a tank over a time duration, $t_{d}$, of less than a few minutes. The value of $t_{d}$ is usually uncertain because of lack of knowledge of key information, such as the size and location of the hole and the pressure and temperature of the chemical. In addition, it is rare that eyewitnesses or video cameras are present at the time of the accident. For inhalation hazards, serious health effects (such as damage to the respiratory system) are determined by short term averages $(<1$ minute) of concentrations, C. It is intuitively obvious that, for a ground level source and with all conditions the same (e.g., the same mass Q released), the maximum $\mathrm{C}$ near the source will be larger for a shorter than a longer release duration, $\mathrm{t}_{\mathrm{d}}$. This paper investigates the variation with downwind distance, $\mathrm{x}$, of the ratio of maximum $\mathrm{C}$ for two time durations of release. Some simplified formulas for dispersion from finite duration releases are presented based on dimensional analysis. A primary dimensionless number of importance is the ratio of the release duration, $t_{d}$, to the travel time $t_{t}=$ $\mathrm{x} / \mathrm{u}$, at distance, $\mathrm{x}$, where $\mathrm{u}$ is wind speed. Examples of applications to pressurized liquefied chlorine releases from tanks are given, focusing on scenarios from the Jack Rabbit I (JR I) field experiment. The analytical calculations and the predictions of the SLAB dense gas dispersion model agree that the ratio of maximum $\mathrm{C}$ for two different $\mathrm{t}_{\mathrm{d}}$ 's is greatest (as much as a factor of ten) near the source. At large 
distances (beyond a few $\mathrm{km}$ for the JR I scenarios), where $t_{t}$ exceeds both $t_{d}$ 's, the ratio of maximum C approaches unity.

Key Words: chemical accidents; chlorine; puff dispersion; plume dispersion; Jack Rabbit field experiment; effects of release duration

\section{Background}

Many hazardous gas releases from valve breaks or tank ruptures have a finite time duration, $t_{d}$, on the order of a few seconds to several minutes (CCPS/AIChE, 1996). The total mass of material, Q, in the tank or in the pipe is given. A number of dispersion models are available as software packages to assess the downwind concentrations resulting from these releases. For example, Hanna et al. (2008) compared the predictions of six of the more widely-used models using inputs from three major chlorine railcar accidents (Festus, Macdona, and Graniteville). For these large (10 to 50 ton) releases of chlorine, the important averaging times, $\mathrm{T}_{\mathrm{a}}$, for concentration, $\mathrm{C}$, are a few minutes or less, since more serious health effects occur at such small $\mathrm{T}_{\mathrm{a}}$ (Sommerville et al., 2007). One way to determine the variation in maximum concentration $\mathrm{C}$ with $t_{d}$ for a given scenario is a brute force method involving running a model many times using a range of values of $t_{d}$ and then choosing the maximum. This can be very time-consuming. A better way to determine the variations in maximum $\mathrm{C}$ with $\mathrm{t}_{\mathrm{d}}$ is to carry out a set of controlled field experiments with side-by-side (but non-interfering) releases with everything the same except $t_{d}$. But field experiments with hazardous substances are expensive and it is difficult to 
47 accumulate enough trials under the same conditions required to produce a statistically significant 48 conclusion.

50 The current paper approaches the estimation of the variation of maximum $\mathrm{C}$ with release 51 duration, $t_{d}$, by using fundamental similarity formulas for continuous plume dispersion, relative

52 (puff) dispersion, and finite duration releases (e.g., Taylor 1921, Batchelor 1950, Pasquill 1974).

53 These formulas can be written as one-line analytical expressions that can be easily manipulated

54 to show how the maximum $\mathrm{C}$ varies as $\mathrm{t}_{\mathrm{d}}$ and other inputs vary. Two Jack Rabbit I (JR I)

55 chlorine field experiment trials (see Fox and Storwold 2011 and Hanna et al. 2012) are used as 56 test cases.

57

58 It is assumed in the derivations in Section 3 that the fundamental release process (e.g., dense 59 momentum jet, evaporation from liquid pool) is unchanged when comparing concentrations for 60 two values of release duration, $t_{d}$. This assumption may not be valid for some release scenarios, 61 such as an initial strong two-phase momentum jet, which may have significant rain-out

62 (deposition of liquid to the surface) and a subsequent period of evaporative release from the 63 liquid pool. In this case the entrainment rates and other processes are different for the two 64 segments of the release.

65

In the case of flammables, where the concentrations of interest (e.g., LFLs) are a few percent, 67 the results in this paper are valid in the near field as long as the $t_{d}$ 's of interest are associated with 68 the same general release scenario. 
If the initial release scenario involves an instantaneous explosion, the concept of two different

$71 t_{d}$ 's is irrelevant, since $t_{d}$ is always near zero and will be much smaller than the travel times to

72 any distance of interest.

73

74 2. Overview of similarity theory of puffs and continuous plumes

75 In the days before computers, scientists put much thought into the derivation of analytical

76 formulas to describe physical phenomena such as the transport and dispersion of materials

77 released into the boundary layer of the atmosphere. Examples are the seminal papers by Taylor

78 (1921) on dispersion of continuous plumes (one-particle dispersion) and Batchelor (1950) on

79 puffs (two-particle or relative dispersion). Pasquill (1974) reviews this literature and unifies the

80 theory so that it is can be applied to time-variable releases, given knowledge of analytical

81 formulas for the spectrum of boundary layer turbulence.

82

83 The atmospheric boundary layer is always turbulent and contains a wide spectrum of space or

84 time scales. The material from any type of pollutant release encounters this full spectrum of

85 motion. Depending on the duration of the release, $t_{d}$, and its initial size, $\sigma_{o}$, different ranges of

86 this full spectrum have more influence on the turbulent dispersion of the material. Turbulent

87 eddies with sizes much larger than the cloud (plume or puff) do not contribute much to the

88 internal cloud dispersion, since all they do is move the cloud around bodily (e.g., a meandering

89 plume). Pasquill (1974) points out that the range of turbulent eddy scales that affect the

90 dispersion can be understood as a "window", in analogy with signal theory, described as high-

91 pass and low-pass filters.

92 
Gifford (1968) and Hanna et al. (1982) comment that the instantaneous cloud width of a continuous release seen in a downward pointing snapshot at a given downwind distance can be considered equivalent to the width of a single puff at that distance. If more snapshots were taken of the plume in rapid sequence over an averaging time period of $\mathrm{T}_{\mathrm{a}}$, and all snapshots laid on top of each other, the width of the averaged plume will gradually increase as $\mathrm{T}_{\mathrm{a}}$ increases. When a large number of cases are considered, the dispersive spread (width) of a time-averaged plume at a given downwind distance is always larger than or equal to the dispersive spread (width) of an instantaneous puff at that distance. Gifford (1968) and Hanna et al. (1982, see Fig. 6.4) present observations of puff and plume widths that demonstrate this difference. The observations show that, depending on the initial cloud size, the wind speed, and the stability, the width of the puff could be as small as $10 \%$ of the width of the continuous plume at positions not far from the source.

\section{Batchelor (1950) used similarity theory to suggest a simple relation for the growth of the} standard deviation, $\sigma$, of a spherical puff. The puff size, as denoted by $\sigma(\mathrm{m})$, is assumed to increase with time due to turbulence in the inertial subrange, which can be characterized by the eddy dissipation rate $\varepsilon\left(\mathrm{m}^{2} / \mathrm{s}^{3}\right)$. The variation of $\sigma$ with travel time, $\mathrm{t}$, is then given by:

$$
\sigma^{2}=\operatorname{cet}^{3}
$$

where $\mathrm{c}$ is a non-dimensional constant that has been determined to be in the range from 0.5 to 2 based on comparisons with field observations. 
The Taylor (1921) equation for the growth of continuous plumes is widely used as the basis

117 for current Lagrangian particle dispersion models. It assumes a Lagrangian turbulent time scale

118 of $\mathrm{T}_{\mathrm{L}}$, and gives $\sigma$ proportional to $\mathrm{t}$ at $\mathrm{t}<<\mathrm{T}_{\mathrm{L}}$ and $\sigma$ proportional to $\mathrm{t}^{1 / 2}$ at $\mathrm{t}>>\mathrm{T}_{\mathrm{L}}$. Thus, based

119 on the Batchelor (1950) and Taylor (1921) equations, at small to intermediate times of travel, the

120 puff $\sigma$ is growing at a greater rate (proportional to $\mathrm{t}^{3 / 2}$ ) than the continuous plume $\sigma$ (proportional

121 to t). As mentioned above, the puff $\sigma$ starts out smaller but asymptotically approaches the plume

$122 \sigma$ at large times of travel.

123

124 Gifford et al. $(1985,1988)$ show that the transition in the Taylor $(1921)$ equation to a $\sigma$

125 proportional to $\mathrm{t}^{1 / 2}$ regime at large travel times or distances seldom occurs in the many sets of

126 atmospheric observations that they analyzed of horizontal dispersion at scales from 20 to 2000

$127 \mathrm{~km}$ (meso to regional scales). They conclude that there are significant magnitudes of horizontal

128 turbulent variations at large time scales (from a few hours up to a day or more). This presence of 129 ever-larger scales of motions causes the lateral standard deviation, $\sigma_{y}$, to continue to increase in 130 proportion to $\mathrm{t}$ and not drop off to a $\mathrm{t}^{1 / 2}$ relation.

131

132 The vertical dispersion, $\sigma_{\mathrm{z}}$, is more strongly influenced than $\sigma_{\mathrm{y}}$ by stability and by the

133 presence of capping inversions (at the top of the boundary layer or at the tropopause), which

134 limit the vertical extent to which plume or puff material can be spread by turbulent mixing. The 135 daytime boundary layer mixing depth is usually about 1 or $2 \mathrm{~km}$ and the tropopause is usually at 136 a height of about 10 to $15 \mathrm{~km}$. But during the daytime, at times less than about $30 \mathrm{~min}$ and

137 distances less than a few $\mathrm{km}$, before the cloud has dispersed throughout the mixed layer, the puff 138 and plume $\sigma_{\mathrm{z}}$ 's follow similar relations as described above for $\sigma_{\mathrm{y}}$. 


\section{Analytical dispersion formulas for puffs and continuous plumes}

We are searching for simple analytical dispersion models that can be manipulated to study the ratio of the arc-maximum cloud centerline concentrations predicted for a given scenario for two different release durations, $t_{d 1}$ and $t_{t 2}$, where $t_{d 1}<t_{d 2}$. We shall assume that the total mass of the

144 release, $\mathrm{Q}$, is constant. This would be consistent with a tank of chlorine where different hole 145 sizes lead to different release durations.

To guide our analysis, we use the Buckingham pi theorem, which states that, given a scientific problem with $\mathrm{N}$ variables and with $\mathrm{M}$ units (e.g., time in s, distance in $\mathrm{m}$ ), then $\mathrm{N}-\mathrm{M}$ independent

149 dimensionless numbers can be created to describe the solution. Our current problem concerns the arc-maximum concentration, $\mathrm{C}$, at downwind distance, $\mathrm{x}$, for wind speed, $\mathrm{u}$, for two different

151 release duration times, $t_{\mathrm{d} 1}$ and $t_{\mathrm{d} 2}$. The averaging time of the concentrations is assumed to be less 152 than $t_{\mathrm{d} 1}$ and $t_{\mathrm{d} 2}$. It is assumed that the initial cloud standard deviation is $\sigma_{\mathrm{o}}$. Thus we have 7

153 variables $\left(\mathrm{C}_{\mathrm{td} 1}, \mathrm{C}_{\mathrm{td} 2}, \mathrm{t}_{\mathrm{d} 1}, \mathrm{t}_{\mathrm{d} 2}, \mathrm{x}, \mathrm{u}, \sigma_{\mathrm{o}}\right)$ and 3 units $(\mathrm{m}, \mathrm{s}$, and $\mathrm{g})$, suggesting that there are $7-3=4$ 154 independent combinations of dimensionless variables. Consequently, an option for the final 155 equation could have the following dimensionless form:

$$
\mathrm{C}_{\mathrm{td} 2} / \mathrm{C}_{\mathrm{td} 1}=\mathrm{f}\left(\mathrm{t}_{\mathrm{d} 1} / \mathrm{t}_{\mathrm{d} 2}, \mathrm{x} / \mathrm{ut}_{\mathrm{d} 2}, \sigma_{\mathrm{o}} / \mathrm{ut}_{\mathrm{d} 2}\right)
$$

159 Note that the ratio $\mathrm{x} / \mathrm{u}$ defines the travel time, $\mathrm{t}_{\mathrm{t}}$, from the source to the distance $\mathrm{x}$. 
Gaussian distributions of concentrations are assumed. The release is assumed to be at ground 162 level and so also is the receptor location. Since we are searching for maximum concentrations, C $163\left(\mathrm{~g} / \mathrm{m}^{3}\right)$ at given downwind distances or times, the formula for concentrations applies to the plume 164 or puff centerline (or arc-maximum). The well-known Gaussian formulas for ground-level 165 centerline concentration for continuous plumes and for instantaneous puffs are:

167 continuous plume $\mathrm{C}=\left(\mathrm{Q} / \mathrm{t}_{\mathrm{d}}\right) /\left(\pi \mathrm{u} \sigma_{\mathrm{yc}} \sigma_{\mathrm{zc}}\right)$

$$
\mathrm{C}=2 \mathrm{Q} /\left((2 \pi)^{3 / 2} \sigma_{\mathrm{xi}} \sigma_{\mathrm{yi}} \sigma_{\mathrm{zi}}\right)
$$

171 For the current problem, wind speed, $\mathrm{u}(\mathrm{m} / \mathrm{s})$, is assumed to apply at a height of $2 \mathrm{~m}$. The lateral 172 and vertical dispersion parameters, $\sigma_{\mathrm{y}}$ and $\sigma_{\mathrm{z}}$, were discussed above, where it was shown that 173 those for instantaneous puffs are always smaller or equal to those for continuous plumes. The 174 along-wind dispersion parameter, $\sigma_{\mathrm{x}}$, is important only if the cloud has a finite duration release. 175 It is irrelevant for continuous plumes, whose back end is always at the source location, and 176 whose front end extends indefinitely past the receptor location.

For clouds with significant excess density, the vertical spread (i.e., $\sigma_{z}$ ) is inhibited and the 179 lateral horizontal spread (i.e., $\sigma_{\mathrm{y}}$ ) is enhanced (see Briggs et al. 2001 and Hanna and Chang 180 2001). Hanna et al. (1993) and Hanna and Chang (2001) find that, when compared with neutral 181 or passive gas dispersion, the reduction in $\sigma_{\mathrm{z}}$ due to density effects is approximately balanced by 182 the enhancement in $\sigma_{\mathrm{y}}$. Thus the product $\sigma_{\mathrm{y}} \sigma_{\mathrm{z}}$ is unchanged as density increases and hence, for 183 continuous plumes, the predicted concentration is unchanged (see Eq. (3)). We will make use of 
184 this finding in later paragraphs. For puffs, where along-wind dispersion, $\sigma_{\mathrm{x}}$, is included, there

185 will be an increase in $\sigma_{\mathrm{x}}$ in dense clouds near the source that could reduce the maximum

186 concentration for dense gases compared with neutral gases.

187

188

Britter and McQuaid (1988) point out that, if $t_{d} \gg t_{t}($ or $x / u)$, the cloud is essentially a continuous plume, and if $t_{d}<<t_{t}$, then the cloud can be thought of as a puff. When $t_{d}$ and $t_{t}$ are of 190 the same order, the cloud is shaped like a "slug", with an elongated central part associated with 191 the release duration $t_{d}$ and of length about $\mathrm{ut}_{\mathrm{d}}$, and with Gaussian-shaped back and front ends of 192 length and shape determined by $\sigma_{\mathrm{x}}$. This shape function with a central core and Gaussian edges was also suggested by Colenbrander (1980) for lateral distributions in dense gas clouds resulting

194 from finite duration evaporation of liquid pools, and used as a basis for the widely-used SLAB model by Ermak (1990). For the slug scenario with finite $t_{d}$, we rewrite Eq. (4) as

$$
\text { instantaneous slug } \quad \mathrm{C}=\mathrm{Q} /\left(\pi\left(\mathrm{ut}_{\mathrm{d}}+(2 \pi)^{1 / 2} \sigma_{\mathrm{xi}}\right) \sigma_{\mathrm{yi}} \sigma_{\mathrm{zi}}\right)
$$

199 This solution approaches the instantaneous puff solution (Eq. (4)) for $\mathrm{ut}_{\mathrm{d}}<<\sigma_{\mathrm{xi}}$. The solution approaches the continuous plume solution (Eq. (3)) for $u_{d}>>\sigma_{x i}$, assuming that $\sigma_{i}=\sigma_{c}$. To 201 simplify the derivations, we drop the $\mathrm{i}$ and c subscripts and just use the symbols $\sigma_{\mathrm{x}}, \sigma_{\mathrm{y}}$, and $\sigma_{\mathrm{z}}$.

The interpretation of the appropriate averaging times, $\mathrm{T}_{\mathrm{a}}$, for determination of the dispersion 204 parameters becomes complicated for finite duration releases. Since the slug in the Eq. (5) 205 formulation is assumed to be an entity with a central core, there is an implied averaging time of $206 \mathrm{t}_{\mathrm{d}}$. 
208 Our main concern in this paper is the ratio of the arc-maximum centerline concentration, C, 209 for two different scenarios with different release time durations, $t_{\mathrm{d} 1}$ and $t_{\mathrm{d} 2}$, and everything else 210 the same. Eq. (5) can be used to calculate this ratio:

211

$$
\mathrm{C}\left(\mathrm{t}_{\mathrm{d} 2}\right) / \mathrm{C}\left(\mathrm{t}_{\mathrm{d} 1}\right)=\left(\mathrm{ut}_{\mathrm{d} 1}+(2 \pi)^{1 / 2} \sigma_{\mathrm{x}}\right) /\left(\mathrm{ut} \mathrm{t}_{\mathrm{d} 2}+(2 \pi)^{1 / 2} \sigma_{\mathrm{x}}\right)
$$

213

214 The along-wind dispersion coefficient $\sigma_{\mathrm{x}}$ is a function of the along-wind turbulence intensity $215 \sigma_{\mathrm{u}} / \mathrm{u}$, the distance $\mathrm{x}$, and a measure of the integral turbulence scale. However, as mentioned 216 earlier, Gifford et al. (1988) found that the horizontal cloud size continues to increase linearly 217 out to travel distances much beyond $2000 \mathrm{~km}$. Thus for the current purposes, we assume the 218 general relation found by Hanna and Franzese (2000), who analyzed many field data sets 219 involving puff releases during the daytime with moderate winds:

220

221

$$
\sigma_{\mathrm{x}}=0.1 \mathrm{x}
$$

223 In reality, nearly all accidental hazardous gas releases have an initial size, defined by $\sigma_{0}$. Thus

$$
\sigma_{\mathrm{x}}=\sigma_{\mathrm{o}}+0.1 \mathrm{x}
$$

227 As mentioned earlier, the initial rate of horizontal spread of a dense gas cloud is larger than that 228 of a neutral cloud. As travel time increases, and concentrations decrease, all clouds become 
229 effectively neutral. Here we assume that Eq. (8) is valid for all densities, and the dense gas

230 effects can be accounted for by increasing $\sigma_{0}$. Substituting Eq. (8) into Eq. (6), we obtain:

231

232

233

234

235

236

237 or

238

239

240

241

242

243

244

245

246

247

248 of nearly the same size.

249

250

251

or

or

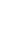

$\left.\left.\mathrm{t}_{\mathrm{t}} / \mathrm{t}_{\mathrm{d} 2}, \sigma_{\mathrm{o}} / \mathrm{ut}_{\mathrm{d} 2}\right)\right]$

2
of nearly the same size.

9

50

$$
\mathrm{C}\left(\mathrm{t}_{\mathrm{d} 2}\right) / \mathrm{C}\left(\mathrm{t}_{\mathrm{d} 1}\right)=\left(\mathrm{ut}_{\mathrm{d} 1}+2.5\left(\sigma_{\mathrm{o}}+0.1 \mathrm{x}\right)\right) /\left(\mathrm{ut}_{\mathrm{d} 2}+2.5\left(\sigma_{\mathrm{o}}+0.1 \mathrm{x}\right)\right)
$$

Since $\mathrm{x} / \mathrm{u}$ is simply the travel time, $\mathrm{t}_{\mathrm{t}}$, from the source to the position $\mathrm{x}$, Eq. (9) can be written:

$$
\mathrm{C}\left(\mathrm{t}_{\mathrm{d} 2}\right) / \mathrm{C}\left(\mathrm{t}_{\mathrm{d} 1}\right)=\left(\mathrm{ut}_{\mathrm{d} 1}+2.5\left(\sigma_{\mathrm{o}}+0.1 \mathrm{ut}_{\mathrm{t}}\right)\right) /\left(\mathrm{ut}_{\mathrm{d} 2}+2.5\left(\sigma_{\mathrm{o}}+0.1 \mathrm{ut}_{\mathrm{t}}\right)\right)
$$

$\mathrm{C}\left(\mathrm{t}_{\mathrm{d} 2}\right) / \mathrm{C}\left(\mathrm{t}_{\mathrm{d} 1}\right)=\left(\mathrm{t}_{\mathrm{d} 1} / \mathrm{t}_{\mathrm{d} 2}+2.5\left(\sigma_{\mathrm{o}} /\left(\mathrm{ut}_{\mathrm{d} 2}\right)+0.1 \mathrm{t}_{\mathrm{t}} / \mathrm{t}_{\mathrm{d} 2}\right)\right) /\left(1+2.5\left(\sigma_{\mathrm{o}} /\left(\mathrm{ut}_{\mathrm{d} 2}\right)+0.1 \mathrm{t}_{\mathrm{t}} / \mathrm{t}_{\mathrm{d} 2}\right)\right)$

Thus Eq. (10b) has the format suggested by the dimensionless Eq. (2) $\left[\mathrm{C}_{\mathrm{td} 2} / \mathrm{C}_{\mathrm{td} 1}=\mathrm{f}\left(\mathrm{t}_{\mathrm{d} 1} / \mathrm{t}_{\mathrm{d} 2}\right.\right.$,

The near-field limiting solution of this equation is $\mathrm{C}\left(\mathrm{t}_{\mathrm{d} 2}\right) / \mathrm{C}\left(\mathrm{t}_{\mathrm{d} 1}\right)=\left(\mathrm{t}_{\mathrm{d} 1} / \mathrm{t}_{\mathrm{d} 2}+2.5 \sigma_{\mathrm{o}} / \mathrm{ut} \mathrm{d}_{\mathrm{d} 2}\right) /(1+$ $\left.2.5 \sigma_{\mathrm{o}} / \mathrm{ut}_{\mathrm{d} 2}\right)$. For situations where $\sigma_{\mathrm{o}} / \mathrm{ut}_{\mathrm{d} 2}$ and $\sigma_{\mathrm{o}} / \mathrm{ut}_{\mathrm{d} 1}$ are $<<1, \mathrm{C}\left(\mathrm{t}_{\mathrm{d} 2}\right) / \mathrm{C}\left(\mathrm{t}_{\mathrm{d} 1}\right)=\mathrm{t}_{\mathrm{d} 1} / \mathrm{t}_{\mathrm{d} 2}($ since for continuous source releases, the release rate $=\mathrm{Q} / \mathrm{t}_{\mathrm{d}}$ ). The far-field limiting solution of the equation is $\mathrm{C}\left(\mathrm{t}_{\mathrm{d} 2}\right) / \mathrm{C}\left(\mathrm{t}_{\mathrm{d} 1}\right)=1$, since as travel time increases, the cloud $\sigma_{\mathrm{x}}$ increases so that eventually it becomes much larger than either ut $\mathrm{d}_{1}$ or $\mathrm{ut}_{\mathrm{d} 2}$ and both clouds are effectively "puffs"

Following the general formulation of the dimensional analysis in Eq. (2), we prepared the example nomogram in Fig. 1. Since a complete solution to Eq. (10b) would require a three- 
252 dimensional plot, our example nomogram assumes a value of $\sigma_{\mathrm{o}} / \mathrm{ut}_{\mathrm{d} 2}=0.0125$ (i.e., the release

253 duration $\mathrm{t}_{\mathrm{d} 2}$ equals 80 times the time taken for the air to traverse a distance $\sigma_{\mathrm{o}}$ ). $\sigma_{\mathrm{o}} / \mathrm{ut}_{\mathrm{d} 2}$ was close

254 to 0.0125 during Trials 2 and 6 at the Jack Rabbit I field experiment involving releases of

255 pressurized liquefied chlorine discussed in the next section. Note that the vertical axis in Fig. 1

256 is $\mathrm{t}_{\mathrm{d} 1} / \mathrm{t}_{\mathrm{d} 2}$ and the horizontal axis is $\mathrm{t}_{\mathrm{t}} / \mathrm{t}_{\mathrm{d} 2}\left(=\mathrm{x} /\left(\mathrm{ut}_{\mathrm{d} 2}\right)\right)$. For the JR I field trials involving releases of

257 pressurized liquefied chlorine from a hole in a one or two ton tank, there is uncertainty regarding

258 the value of $t_{d}$, since the videos did not show a sharp cessation of the two-phase jet, and some of

259 the dense chlorine cloud remained in the depression around the source and was subsequently

260 detrained into the ambient air flow. The following asymptotes are seen on the figure: 1 ) as $t_{\mathrm{d} 1} / \mathrm{t}_{\mathrm{d} 2}$

261 approaches unity, $\mathrm{C}\left(\mathrm{t}_{\mathrm{d} 2}\right) / \mathrm{C}\left(\mathrm{t}_{\mathrm{d} 1}\right)$ approaches unity; and 2) as $\mathrm{t}_{\mathrm{t}} / \mathrm{t}_{\mathrm{d} 2}$ increases, the ratio $\mathrm{C}\left(\mathrm{t}_{\mathrm{d} 2}\right) / \mathrm{C}\left(\mathrm{t}_{\mathrm{d} 1}\right)$

262 approaches unity. The latter fact was previously explained as being the result of the fact that

263 both clouds are effectively puffs of the same size at such large times or distances.

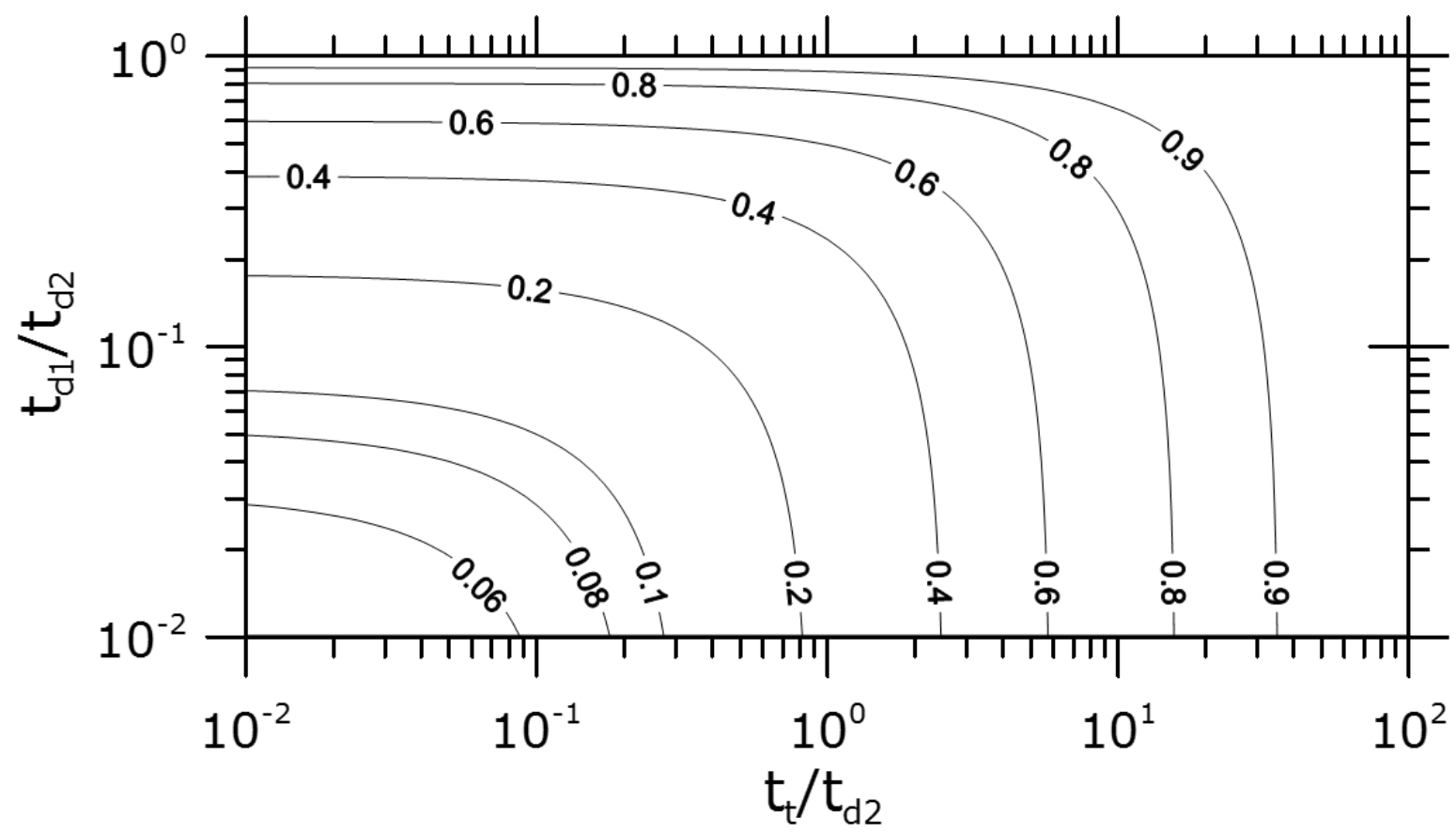


Fig. 1. Contours of the $\mathrm{C}\left(\mathrm{t}_{\mathrm{d} 2}\right) / \mathrm{C}\left(\mathrm{t}_{\mathrm{d} 1}\right)$ solution to Eq. $10 \mathrm{~b}$ for $\sigma_{\mathrm{o}} / \mathrm{ut}_{\mathrm{d} 2}=0.0125$.

\section{Application to the Jack Rabbit I field experiment}

273 and Storwold (2011) provide a detailed description of the JR I experiment and Hanna et al.

274 (2012, 2016) describe analyses of the downwind dispersion observations. A depression (basin)

$27550 \mathrm{~m}$ in diameter and $2 \mathrm{~m}$ deep was dug in the desert surface. A two-ton tank was placed in the

276 center of the depression, with a release valve, with diameter $8 \mathrm{~cm}$, located at the bottom of the

277 tank about $2 \mathrm{~m}$ above ground (see Fig. 2). The jet was intentionally directed downwards, to

278 maximize the near-field cloud impact. Releases took place just after dawn on clear summer

279 mornings, when the ambient atmosphere was stable. Wind speeds during the five chlorine trials

280 were usually low (about $2 \mathrm{~m} / \mathrm{s}$ or less), except for one trial with $6.2 \mathrm{~m} / \mathrm{s}$. The downward pointing

281 jet and the depression would tend to keep the chlorine close to the source location for as long as

282 possible, especially during periods with light winds.

In the five JR I experiment trials involving chlorine, the tank emptied in about 30-60 s, with a 285 powerful momentum jet seen on the videos. The flashing near the valve resulted in a two phase 286 mixture containing about $20 \%$ vapor and $80 \%$ liquid (by mass), with the liquid in the form of 287 small drops with diameters likely in the range from about 20 to $100 \mu \mathrm{m}$. As described by Hanna 288 et al. (2012), a significant fraction of the airborne mass (gas and small aerosol mixture) that was 
289 released did not initially escape the depression (i.e., it was "held-up") when the ambient wind 290 speed was less than 2 or $3 \mathrm{~m} / \mathrm{s}$. Fig. 2 contains two photographs of the cloud during Trial 2, 291 which had the smallest wind speed, $0.6 \mathrm{~m} / \mathrm{s}$, during JR I. The top photograph shows the initial 292 momentum jet, which lasted about $30 \mathrm{~s}$, and the bottom photograph illustrates the calm dense 293 cloud held-up in the depression. The videos show that the chlorine gas was subsequently 294 detrained into the overlying ambient flow over a time period of about $32 \mathrm{~min}(1920 \mathrm{~s})$ for this 295 Trial. Thus, from the point of view of transport and dispersion in the overlying ambient 296 boundary layer, the release duration time, $\mathrm{t}_{\mathrm{d}}$, for Trial 2 was actually $1920 \mathrm{~s}$, even though most of 297 the chlorine was released from the tank in only $30 \mathrm{s.}$

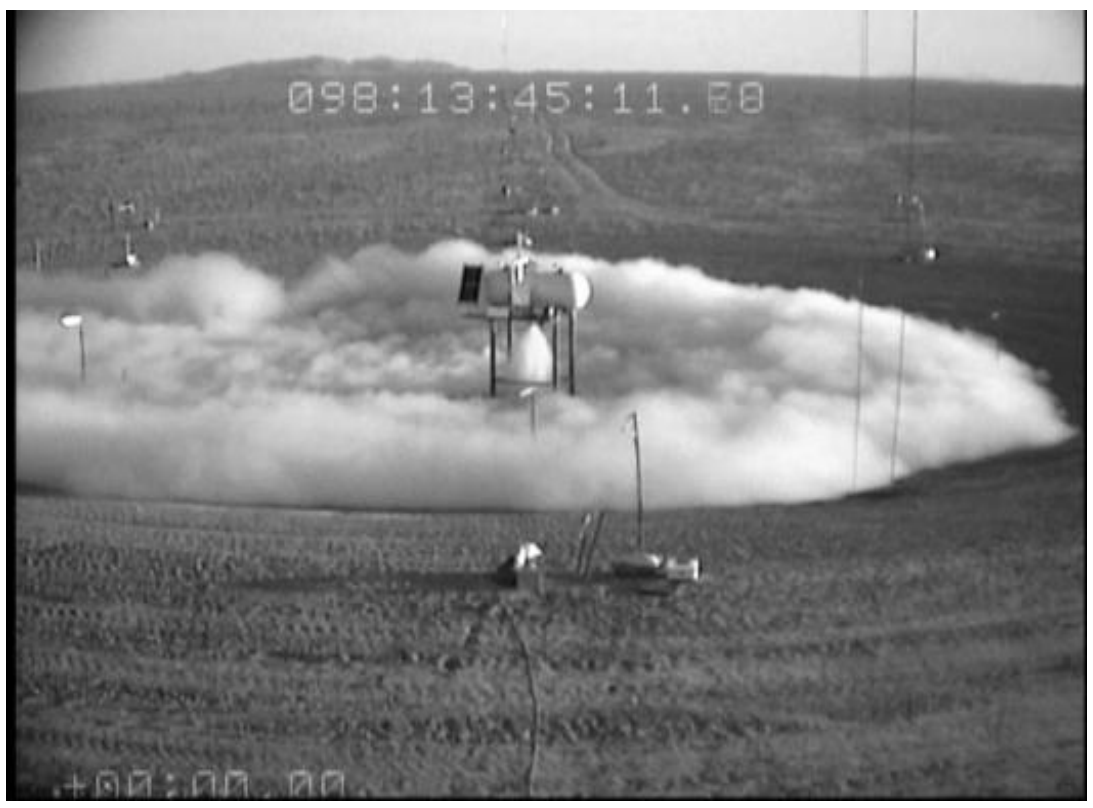




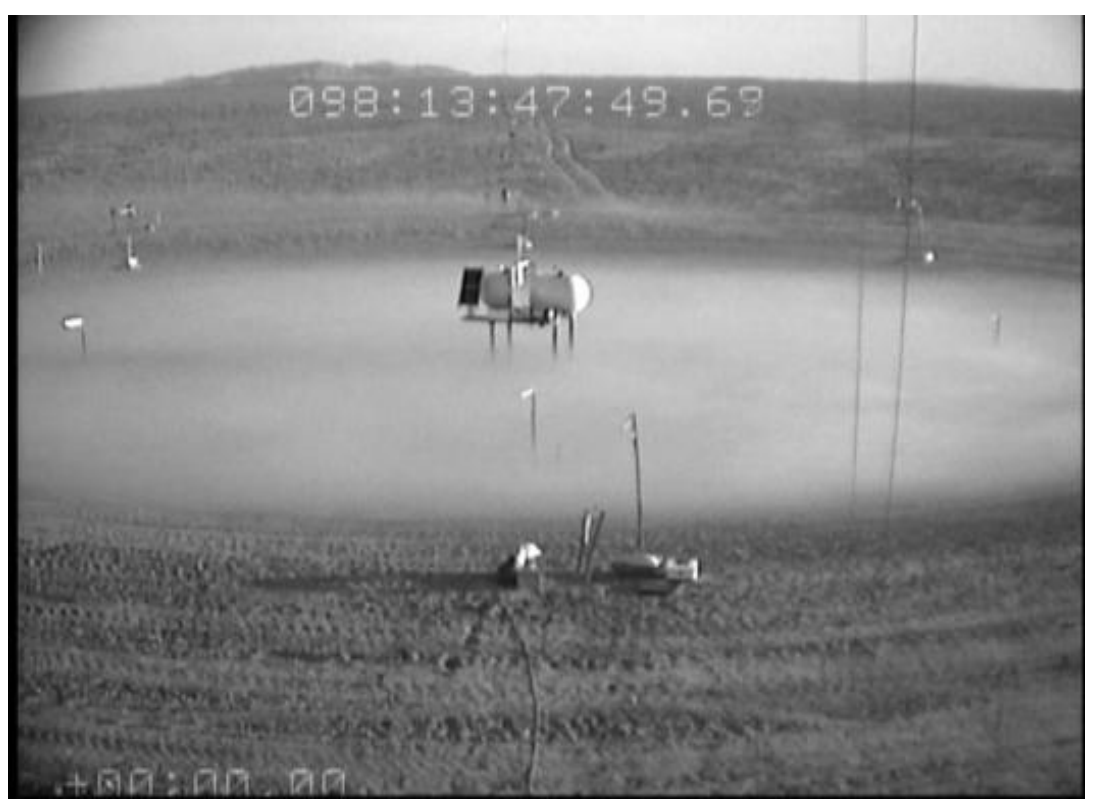

303 Fig. 2. Jack Rabbit I Trial $2(\mathrm{u}=0.6 \mathrm{~m} / \mathrm{s})$ visible chlorine cloud behavior at $22 \mathrm{~s}$ (top) and at 180 $304 \mathrm{~s}$ (bottom) after the release began. The pressurized release from the tank ceased at about $30 \mathrm{~s}$.

Another of the JR I chlorine trials (Trial 6) took place during a period with larger ambient 308 wind speeds $(6.2 \mathrm{~m} / \mathrm{s})$ and minimal "hold-up" in the depression was observed in that case (see 309 Fig. 3). The chlorine cloud appeared as a typical plume that moved off downwind. This 310 behavior agreed with fundamental theory for detrainment of dense clouds held up in a depression 311 (Hanna et al., 2012). In this case, the videos of the jet suggest that $t_{d}$ is about 30 to $60 \mathrm{~s}$, with 312 some uncertainty concerning the time that the jet release ended. 


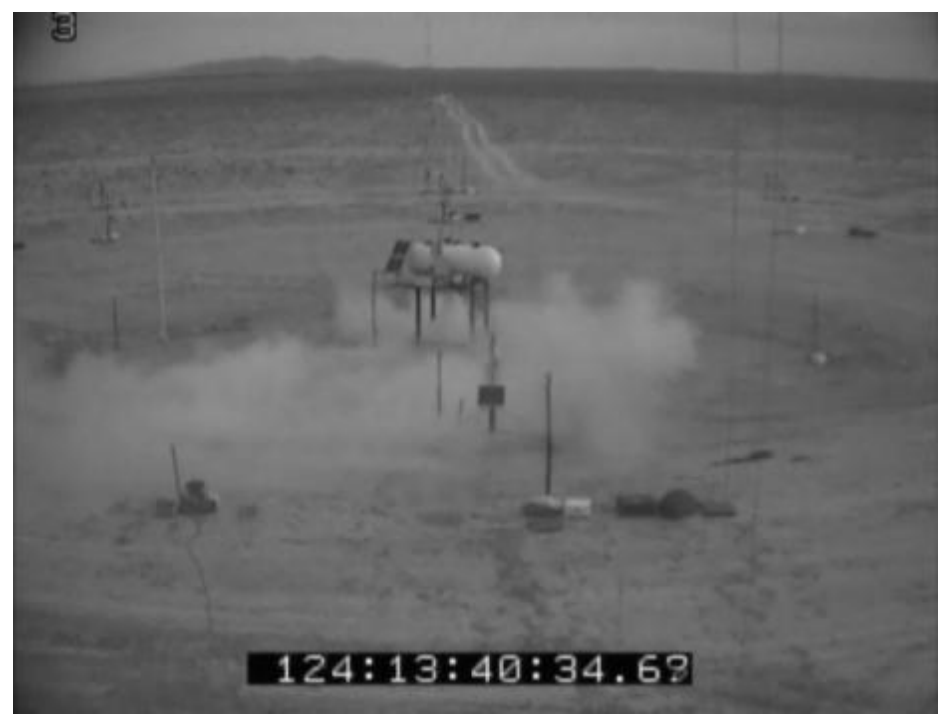

317 Fig. 3. Jack Rabbit I Trial $6(\mathrm{u}=6.2 \mathrm{~m} / \mathrm{s})$ visible chlorine cloud behavior at $34 \mathrm{~s}$ after the release 318 began.

In the next section we apply Eq. (10b) to JR I Trials 2 and 6. We also compare the results for 321 Trial 6 with calculations by the widely-used dense gas dispersion model, SLAB (Ermak, 1990).

\section{Effects of duration of release on JR I Trial 2 and 6 simulated concentrations}

327 two possible assumptions for release duration $-t_{d 1}$ of $30 \mathrm{~s}$ (corresponding to the time taken to 328 empty the tank and the duration of the strong two-phase momentum jet), and $\mathrm{t}_{\mathrm{d} 2}$ of $1920 \mathrm{~s}$

329 (corresponding to the time taken for all the gas in the depression to be entrained into the overriding ambient air; see Hanna et al., 2012). Assume that the initial standard deviation $\sigma_{0}$, is 
$33114.4 \mathrm{~m}$ (the standard deviation of a uniform distribution over the $50 \mathrm{~m}$ width of the depression

332 seen in Fig. 2). Intuitively, it is expected that concentrations will be larger for the smaller $t_{d}$ than

333 for the larger $t_{d}$, since the mass emission rate is larger for the smaller $t_{d}$. The analytical Eq. (10b)

334 yields the results listed in Table 1 for the ratios of the concentrations for the $t_{d 1}=30 \mathrm{~s}$ and the $t_{d 2}$

$335=1920$ s release

336

337 As suggested in the previous section, Table 1 shows that the calculated (analytical) ratio $\mathrm{C}\left(\mathrm{t}_{\mathrm{d} 2}\right.$

$338=1920 \mathrm{~s}) / \mathrm{C}\left(\mathrm{t}_{\mathrm{d} 1}=30 \mathrm{~s}\right)$ is smallest (about 0.05 in this case) at the edge of the depression $(\mathrm{x}=25$

$339 \mathrm{~m}$ ) and slowly approaches unity at large distances. Eq. (10b) suggests that, at small distances,

340 where $t_{\mathrm{d} 1}$ has a large influence, for all other conditions the same, the concentration ratios are

341 approximately proportional to $t_{d 1}$. For example, for $t_{d 1}=15 \mathrm{~s}$ instead of $30 \mathrm{~s}$, the ratio in Table 1

342 at $\mathrm{x}=25 \mathrm{~m}$ would decrease by almost a factor of $30 \mathrm{~s} / 15 \mathrm{~s}=2$.

343

344

345 $346 \mathrm{~s}$ release for JR I Trial 2 scenario $\left(\mathrm{u}=0.6 \mathrm{~m} / \mathrm{s}\right.$ and $\left.\sigma_{\mathrm{o}}=14.4 \mathrm{~m}\right)$.

347

348

349

350

351

352

353

354

355

356

357

358

Table 1. Analytical ratios of concentrations for $t_{d 2}=1920 \mathrm{~s}$ release to concentrations for $t_{d 1}=30$

7

8

$$
\mathrm{x}(\mathrm{m}) \quad \mathrm{C}\left(\mathrm{t}_{\mathrm{d} 2}=1920 \mathrm{~s}\right) / \mathrm{C}\left(\mathrm{t}_{\mathrm{d} 1}=30 \mathrm{~s}\right)
$$

analytical solution

50

1

3

$-154$

55

56

$100 \quad 0.065$

$200 \quad 0.084$

$500 \quad 0.136$

$1000 \quad 0.211$

$2000 \quad 0.328$

$5000 \quad 0.535$

$10000 \quad 0.694$


Note that, for the two Trial $2 t_{d}$ values considered in Table 1, the distance at which $t_{d}=t_{t}$ is 18 $362 \mathrm{~m}$ for the $t_{\mathrm{d} 1}=30 \mathrm{~s}$ case and is $1152 \mathrm{~m}$ for the $t_{\mathrm{d} 2}=1920 \mathrm{~s}$ case. This is the distance where the 363 length of the central core or slug $\left(u_{d}\right)$ equals the downwind distance, $x$, and can be thought of as 364 where the cloud is transitioning from being "like a plume" to being "like a puff".

For Trial $2, \sigma_{\mathrm{o}} / \mathrm{ut}_{\mathrm{d} 2}=0.0125$, which is the value assumed in preparing the nomogram in Fig. 1. The solution for Trial 2 on Fig. 1 would be a horizontal line at $t_{\mathrm{d} 1} / t_{\mathrm{d} 2}=0.0156$. The four order of magnitude range in $t_{t} / t_{d 2}$ on the horizontal axis corresponds to downwind distances from $11.5 \mathrm{~m}$ to $115 \mathrm{~km}$.

The analytical Eq. (10b) was also applied to JR I Trial 6, where the wind speed was relatively 372 large $(6.2 \mathrm{~m} / \mathrm{s})$ and there was much less "hold-up" in the depression. Still, there was about a 373 factor of two uncertainty in the duration of the release (from $t_{d 1}=30$ to $t_{d 2}=60 \mathrm{~s}$ ), based on 374 review of the videos. As seen in Fig. 3 for Trial 6, the initial cloud spread $\sigma_{\mathrm{o}}$ is smaller than seen 375 in Fig. 2 for Trial 2. We assume that $\sigma_{\mathrm{o}}$ is $5 \mathrm{~m}$ for Trial 6. Table 2 contains the Eq. (10b) 376 estimates of the concentration ratio for these $t_{d}$ options and for $u=6.2 \mathrm{~m} / \mathrm{s}$ and $\sigma_{o}=5 \mathrm{~m}$. Here 377 the ratio is larger (closer to unity) than in Table 1, because the difference between the two $t_{d}$ 378 values is smaller. The analytical formula predicts a ratio of 0.52 at the edge of the depression ( $\mathrm{x}$ $379=25 \mathrm{~m}$ ) and a ratio of 0.94 at a distance of $10 \mathrm{~km}$. The SLAB dense gas model predictions of the 380 concentration ratios for $\mathrm{t}_{\mathrm{d} 1}=30 \mathrm{~s}$ and $\mathrm{t}_{\mathrm{d} 2}=60 \mathrm{~s}$ are also listed in Table 2 , and are consistently 381 only about $10 \%$ smaller than the ratios calculated with the analytical formula. Note that the 
382 analytical and SLAB solutions in the near-field are close to 0.5, which is the asymptotic limit of 383 Eq. (10b) for $\mathrm{t}_{\mathrm{d} 1}=30$ and $\mathrm{t}_{\mathrm{d} 2}=60 \mathrm{~s}$.

385 Table 2. Analytical and SLAB modeled ratios of concentrations for $t_{\mathrm{d} 2}=60 \mathrm{~s}$ release to concentrations for $t_{d 1}=30 \mathrm{~s}$ release for JR I Trial 6 scenario $\left(u=6.2 \mathrm{~m} / \mathrm{s}\right.$ and $\left.\sigma_{\mathrm{o}}=5 \mathrm{~m}\right)$.

387

388

389

390

391

392

393

394

395

396

397

398

399

400

401

402

403

404

405

406

407

.

408 Observations of arc-maximum observed concentrations during Trial 6 are compared with 409 SLAB predictions for $t_{d 1}=30$ and $t_{d 2}=60 \mathrm{~s}$ in Fig. 4. As suggested by comparing the analytical

$$
\mathrm{x}(\mathrm{m}) \quad \mathrm{C}\left(\mathrm{t}_{\mathrm{d} 2}=60 \mathrm{~s}\right) / \mathrm{C}\left(\mathrm{t}_{\mathrm{d} 1}=30 \mathrm{~s}\right)
$$

analytical $\quad \underline{\mathrm{SLAB}}$

$\begin{array}{rll}25 & 0.52 & 0.47 \\ 50 & 0.53 & 0.47 \\ 100 & 0.55 & 0.47 \\ 200 & 0.57 & 0.49 \\ 500 & 0.64 & 0.60 \\ 1000 & 0.72 & 0.68 \\ 2000 & 0.79 & 0.71 \\ 5000 & 0.89 & \text { not available } \\ 10000 & 0.94 & \text { not available }\end{array}$

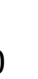

1

The nomogram in Figure 1 has been prepared assuming a value of 0.0125 for $\sigma_{\mathrm{o}} / \mathrm{ut}_{\mathrm{d} 2}$. For trail $6, \sigma_{\mathrm{o}} / \mathrm{ut}_{\mathrm{d} 2}=0.0134$, which is close enough to the value assumed for Figure 1 that we can assume that the nomogram can be applied to Trial 6. The solution for Trial 6 would therefore be the horizontal line at $t_{\mathrm{d} 1} / t_{\mathrm{d} 2}=0.5$ in Figure 1, and the four orders of magnitude on the abscissa would represent downwind distances from $3.8 \mathrm{~m}$ to $37.8 \mathrm{~km}$. 
410 formula and SLAB concentration ratios listed in Table 2, the fractional difference in the SLAB

411 predictions for $t_{\mathrm{d} 1}=30$ and $t_{\mathrm{d} 2}=60 \mathrm{~s}$ are seen to gradually decrease as distance increases. At

412 large distances, both clouds are dispersing essentially as puffs, since $t_{t}=x / u \gg t_{d}$ for both

413 release durations.

414

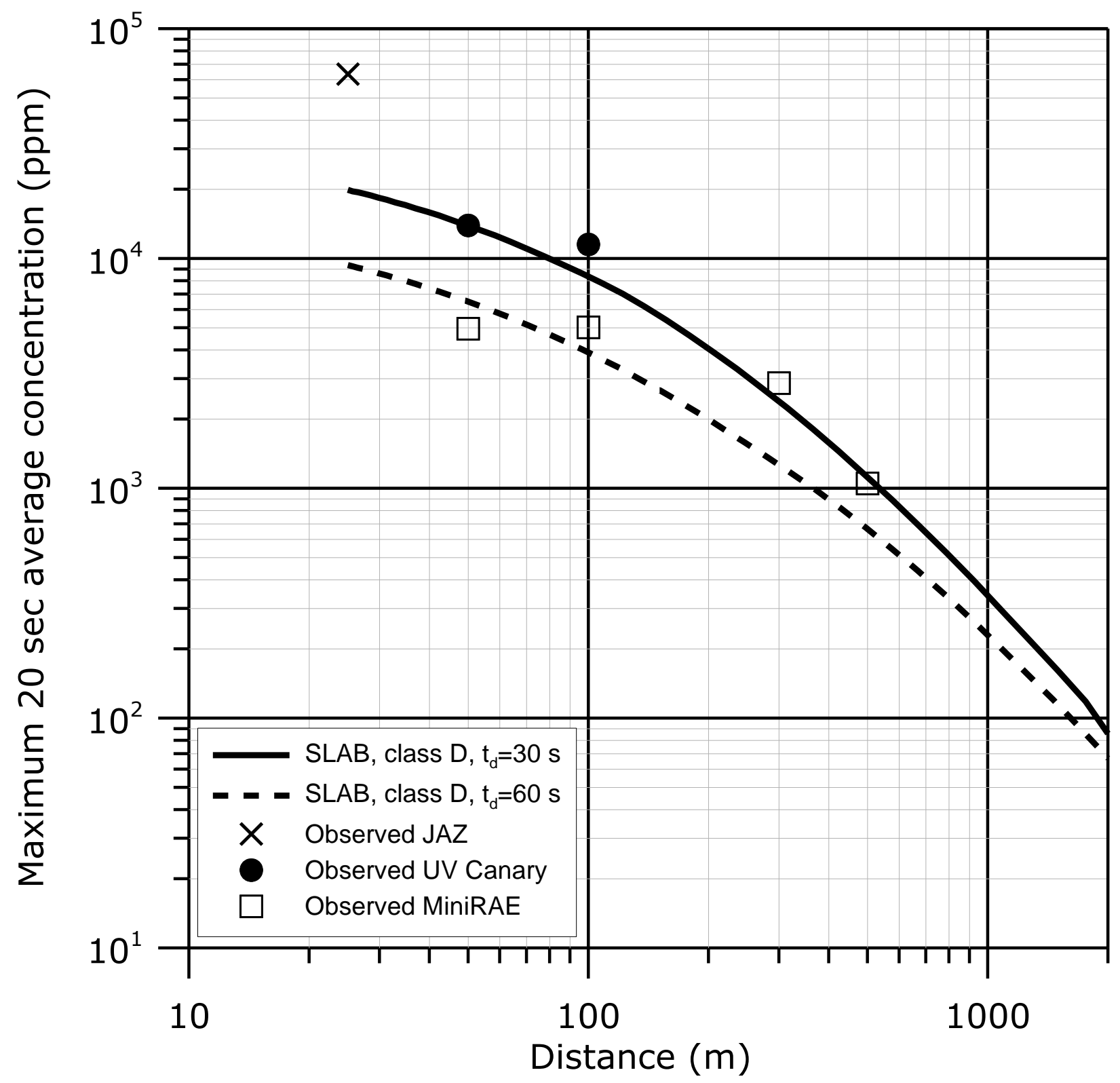


417 Fig. 4. Concentrations predicted by SLAB for JR I Trial 6 for $t_{d}=30 \mathrm{~s}$ and $60 \mathrm{~s}$, compared with 418 sampler (JAZ, Canary, MiniRAE) observations. The SLAB predictions were used to calculate 419 the ratios presented in Table 2.

\section{Practical guidance and caveats}

423

The scenario of interest in this paper is the accidental release of a pressurized liquefied gas 425 from a hole in a storage tank or pipe. There is a fixed mass, Q, in the tank or pipe segment. In 426 the JR I experiments, with Q of one or two tons and hole sizes of 8 to $10 \mathrm{~cm}$, the initial high427 momentum jet release lasts for about $30 \mathrm{~s}$ to $60 \mathrm{~s}$. The analytical solution and the SLAB dense 428 gas dispersion model agree that, for a constant mass released, Q, and all other conditions the 429 same, an increase in the duration of release, $t_{d}$, can significantly decrease the predicted cloud 430 maximum concentration in the near-field. However, for concentrations at large distances or 431 travel times $\left(t_{t}=x / u>t_{d}\right)$, the reductions in concentration steadily decrease. At such large 432 distances or travel times, the cloud looks like a puff with nearly the same $\sigma_{\mathrm{x}}$ no matter what the 433 release duration.

We have been assuming that the mass release occurs at ground level. Otherwise, if there is a 436 significant stack height or plume rise (due to momentum effects), the cloud may remain aloft for 437 a while near the source. As a result, the near-field ground-level concentrations would likely be 438 nearly zero until the base of the elevated cloud reaches ground level farther downwind. 
As discussed in the section describing differences between the cloud spreads of puffs and continuous plumes, there may be an additional increase in concentration for the case with smaller

$442 t_{d}$ due to the fact that the spread (e.g., $\left.\sigma_{y}\right)$ of a puff is less than that of a continuous plume. We

443 have not accounted for that difference in the analytical solution. Furthermore, we have

444 arbitrarily assumed an initial spread, $\sigma_{\mathrm{o}}$, based on visual inspection of the JR I videos and photos.

445 That assumption could have a large effect on the maximum $\mathrm{C}$ difference very near the source.

The analytical approach is less useful if the release scenarios are significantly different for the two $t_{d}$ options (e.g., if one $t_{d}$ is primarily associated with a two-phase momentum jet and the

449 other with a liquid spill and subsequent evaporation). However, as for the examples used above, 450 at large downwind distances, even the release scenario may become unimportant, since, for the 451 same total mass released, the resulting cloud in either case is a well-dispersed puff and is 452 essentially neutral or passive.

Despite the caveats, the fundamental result appears to be supported by theory and by 455 operational model application - for typical large releases of pressurized liquefied gases, the 456 differences in cloud centerline $\mathrm{C}$ due to differences in $\mathrm{t}_{\mathrm{d}}$ are largest near the source and become 457 insignificant at distances of 5 to $10 \mathrm{~km}$ and beyond.

The same general approach regarding effects of release duration would also apply to non460 reactive releases of other chemicals for other scenarios and scales. The sizes of hazard areas 461 could be vastly different depending on the magnitude of the release and the hazard threshold. 462 For example, suppose there was a large release, near ground level, of radiological pollutants 
463 from a nuclear power plant incident. The two release durations in question might be $\mathrm{t}_{\mathrm{d} 1}=6$

464 hours and $t_{\mathrm{d} 2}=6$ days. Although a comprehensive modeling approach might involve a detailed

465 numerical weather prediction model and a Lagrangian particle or puff dispersion model, a first-

466 cut estimate of the ratios of expected arc-maximum concentrations can be made with Eq. (10b).

467 The concentration ratio is likely to be $0.042(6 \mathrm{hrs} / 144 \mathrm{hrs})$ at cloud travel times less than $6 \mathrm{hrs}$

468 (or downwind distances less than $216 \mathrm{~km}$ for a wind speed of $10 \mathrm{~m} / \mathrm{s}$ ). At travel times much

469 greater than 6 days (or distances greater than about $5200 \mathrm{~km}$ ), the concentration ratio approaches

470 unity.

471

472 Acknowledgements - This research was sponsored by the U.S. Department of Homeland

473 Security (DHS) and by the U.S. Defense Threat Reduction Agency (DTRA).

474

475 References

476

477 Batchelor, G.K., 1950. Application of the similarity theory of turbulence to atmospheric diffusion. Q. J.

478 Roy. Met. Soc. 76(328), 133-146.

479

480 Briggs, G.A., Britter, R.E., Hanna, S.R., Havens, J.A., Robins, A.G., Snyder, W.H., 2001. Dense gas

481 vertical diffusion over rough surfaces: results of wind-tunnel studies. Atmos. Environ. 35, 2265-2284.

482

483 Britter, R.E., McQuaid, J., 1988. Workbook on the Dispersion of Dense Gases. HSE Contract Research

484 Report No. 17/1988, Health and Safety Executive, Sheffield, UK, 158 pp.

485 
486 Colenbrander, G.W., 1980. A mathematical model for the transient behavior of dense vapor clouds.

487 Proc., Third Int. Symp. on Loss Prevention and Safety Promotion in the Process Industries, Vol. 3, Paper

$488 \quad 15,1104-1132$.

489

490

CCPS/AIChE, 1996. Guidelines for Use of Vapor Cloud Dispersion Models. AIChE/CCPS, 345 East 47th

491 St., New York, NY, 285 pp + CD

492

493 Ermak, D.L., 1990. User's Manual for SLAB: An Atmospheric Dispersion Model for

494 Denser-than-Air Releases, UCRL-MA-105607, Lawrence Livermore Nat Lab, Livermore,

495 CA.

496

497 Fox, S.B., Storwold, D., 2011. Project Jack Rabbit: Field Tests, Chemical Security Analysis

498 Center, Science and Technology Directorate, U.S. Department of Homeland

499 Security, CSAC 11-006, 162 pp.

500

501 Gifford, F.A., 1968. An outline of theories of diffusion in the lower layers of the atmosphere. In

502 Meteorology and Atomic Energy - 1968, D.H. Slade (Ed.), USAEC Report TID-24190, U.S. AEC Report

503 TID-24190, NTIS, pp 66-116.

504

505 Gifford, F.A., 1985. Atmospheric diffusion in the range 20 to $2000 \mathrm{~km}$. Air Pollution Modeling and Its 506 Applications. Plenum Press, 247-265.

507

508 Gifford, F.A., Barr, S., Malone, R.C., Moroz, E.J., 1988. Tropospheric relative diffusion to hemispheric 509 scales. Atmos. Environ. 22, 1871-1879

510 
511 Hanna, S., Briggs, G, Hosker, R, 1982. Handbook on Atmospheric Diffusion. DOE/TIC-11223 USDOE, $512102 \mathrm{pp}$.

513

514 Hanna, S., Britter, R., Argenta, E., Chang, J., 2012. The Jack Rabbit chlorine release experiments; dense 515 gas removal from a depression by crosswinds. J. Haz. Mat. 213-214, 406-412.

516

517 Hanna, S.R., Chang, J.C., 2001. Use of the Kit Fox data to analyze dense gas dispersion modeling issues.

518 Atmos. Environ. 35, 2231-2242.

519

520 Hanna, S.R., Chang, J.C., Huq, P., 2016. Observed chlorine concentrations during Jack Rabbit I and 521 Lyme Bay field experiments. Atmos. Environ. 125, 252-256

522

523 Hanna, S.R., Chang, J.C., Strimaitis, D.G., 1993. Hazardous gas model evaluation with field observations. 524 Atmos. Environ. 27A, 2265-2285.

525

526 Hanna, S.R., Dharmavaram, S., Zhang, J., Sykes, I., Witlox, H., Khajehnajafi, S., Koslan, K., 2008.

527 Comparison of six widely-used dense gas dispersion models for three recent chlorine railcar accidents.

528 Proc. Safety Prog. 27, 248-259

529

530 Hanna, S.R., Franzese, P., 2000. Along wind dispersion - a simple similarity formula compared with

531 observations at 13 field sites and in one wind tunnel. J. Appl, Meteorol. 39, 1700-1714.

532

533 Pasquill., F., 1974. Atmospheric Diffusion, $2^{\text {nd }}$ ed., John Wiley and Sons, New York, 429 pp. 534 
535 Sommerville, D., J. Bray, S. Reutter-Christy, E. Shelly, 2007. Review and Assessment of Chlorine

536 Mammalian Lethality Data and the Development of a Human Estimate. CBRNIAC Contract \#STO-700-

537 00-D-3180, Task 328, Delivery order 483, US Army Edgewood Chemical and Biological Center,

538 Aberdeen Proving Ground, MD 126 pp.

539

540 Taylor, G.I., 1921. Diffusion by continuous movements. Proc. London Math. Soc. 20, 196.

541 


\section{$542 \quad$ List of Figures}

543

544 Fig. 1. Contours of the $\mathrm{C}\left(\mathrm{t}_{\mathrm{d} 2}\right) / \mathrm{C}\left(\mathrm{t}_{\mathrm{d} 1}\right)$ solution to Eq. $(10 \mathrm{~b})$ for $\sigma_{\mathrm{o}} / \mathrm{ut}_{\mathrm{d} 2}=0.0125$.

545

546 Fig. 2. Jack Rabbit I Trial $2(\mathrm{u}=0.6 \mathrm{~m} / \mathrm{s})$ visible chlorine cloud behavior at $22 \mathrm{~s}$ (top) and at 180

$547 \mathrm{~s}$ (bottom) after the release began. The pressurized release from the tank ceased at about $30 \mathrm{~s}$.

548

549 Fig. 3. Jack Rabbit I Trial $6(\mathrm{u}=6.2 \mathrm{~m} / \mathrm{s})$ visible chlorine cloud behavior at $34 \mathrm{~s}$ after the release 550 began.

551

552 Fig. 4. Concentrations predicted by SLAB for JR I Trial 6 for $t_{d}=30 \mathrm{~s}$ and $60 \mathrm{~s}$, compared with 553 sampler (JAZ, Canary, MiniRAE) observations. The SLAB predictions were used to calculate 554 the ratios presented in Table 2.

555

$556 \quad$ List of Tables

557

558

Table 1. Analytical ratios of concentrations for $\mathrm{t}_{\mathrm{d} 2}=1920 \mathrm{~s}$ release to concentrations for $\mathrm{t}_{\mathrm{d} 1}=30$

$559 \mathrm{~s}$ release for JR I Trial 2 scenario $\left(\mathrm{u}=0.6 \mathrm{~m} / \mathrm{s}\right.$ and $\left.\sigma_{\mathrm{o}}=14.4 \mathrm{~m}\right)$.

560

561 Table 2. Analytical and SLAB modeled ratios of concentrations for $t_{\mathrm{d} 2}=60 \mathrm{~s}$ release to

562 concentrations for $\mathrm{t}_{\mathrm{d} 1}=30 \mathrm{~s}$ release for JR I Trial 6 scenario $\left(\mathrm{u}=6.2 \mathrm{~m} / \mathrm{s}\right.$ and $\left.\sigma_{\mathrm{o}}=5 \mathrm{~m}\right)$. 